\title{
Influence of exogenous ascorbic acid and glutathione priming on mitochondrial structural and functional systems to alleviate aging damage in oat seeds
}

Fangshan Xia ${ }^{1,2}$, Hang Cheng ${ }^{2}$, Lingling Chen², Huisen Zhu' ${ }^{1}$ Peisheng Mao ${ }^{2 *}$ and Mingya Wang ${ }^{2}$

\begin{abstract}
Background: Loss of vigor caused by seed aging adversely affects agricultural production under natural conditions. However, priming is an economical and effective method for improving the vigor of aged seeds. The objective of this study was to test the effectiveness of exogenous ascorbic acid (ASC) and glutathione (GSH) priming in the repairing of aged oat (Avena sativa) seeds, and to test the hypothesis that structural and functional systems in mitochondria were involved in this process.

Results: Oat seeds were artificially aged for 20 days at $45^{\circ} \mathrm{C}$, and were primed with solutions $\left(1 \mathrm{mmol} \mathrm{L}^{-1}\right)$ of ASC, $\mathrm{GSH}$, or ASC $+\mathrm{GSH}$ at $20^{\circ} \mathrm{C}$ for $0.5 \mathrm{~h}$ before or after their aging. Seed germination, antioxidant enzymes in the ASC-GSH cycle, cytochrome c oxidase (COX) and mitochondrial malate dehydrogenase $(\mathrm{MDH})$ activities, and the mitochondrial ultrastructures of the embryonic root cells were markedly improved in aged oat seeds through post-priming with ASC, $\mathrm{GSH}$, or ASC $+\mathrm{GSH}$, while their malondialdehyde and $\mathrm{H}_{2} \mathrm{O}_{2}$ contents decreased significantly $(P<0.05)$.

Conclusion: Our results suggested that priming with ASC, GSH, or ASC + GSH after aging could effectively alleviate aging damage in oat seeds, and that the role of ASC was more effective than GSH, but positive effects of post-priming with ASC and GSH were not superior to post-priming with ASC in repairing aging damage of aged oat seeds. However, pre-priming with ASC, GSH, or ASC + GSH was not effective in oat seeds, suggesting that pre-priming with ASC, GSH, or ASC + GSH could not inhibit the occurrence of aging damage in oat seeds.
\end{abstract}

Keywords: Ascorbic acid-glutathione cycle, Mitochondria, Oat, Seed aging, Seed priming

\section{Background}

Seed aging, resulting in a loss of vigor and viability under natural storage conditions, is a major problem for successful agricultural production and productivity. Moreover, seed aging also leads to ecological problems due to shortages of genetic resources and soil seed bank systems dysfunction, e.g., loss of plant biodiversity, grassland

\footnotetext{
*Correspondence: maops@cau.edu.cn

${ }^{2}$ Forage Seed Laboratory/Beijing Key Laboratory of Grassland Science, China Agricultural University, No 2, Yuanmingyuan West Road, Haidian Distr, Beijing 100193, China

Full list of author information is available at the end of the article
}

degeneration, and the enhancement of desertification [1]. Thus, loss of seed vigor is a major challenge for food and ecological security under natural conditions [2]. As a result, it is necessary to better understand the possible methods and mechanisms of maintaining seed vigor.

Accumulation of reactive oxygen species (ROS) is a primary cause of seed aging during storage, causing lipid peroxidation, impairment of RNA and protein synthesis, degradation of DNA, and loss of membrane integrity [3, 4]. The levels of ROS are tightly controlled by enzymatic and non-enzymatic antioxidant systems during seed

(c) The Author(s). 2020 Open Access This article is licensed under a Creative Commons Attribution 4.0 International License, which permits use, sharing, adaptation, distribution and reproduction in any medium or format, as long as you give appropriate credit to the original author(s) and the source, provide a link to the Creative Commons licence, and indicate if changes were made. The images or other third party material in this article are included in the article's Creative Commons licence, unless indicated otherwise in a credit line to the material. If material is not included in the article's Creative Commons licence and your intended use is not permitted by statutory regulation or exceeds the permitted use, you will need to obtain permission directly from the copyright holder. To view a copy of this licence, visit http://creativecommons.org/licenses/by/4.0/ The Creative Commons Public Domain Dedication waiver (http://creativecommons.org/publicdomain/zero/1.0/) applies to the data made available in this article, unless otherwise stated in a credit line to the data. 
aging [1]. Once $\mathrm{O}_{2}{ }^{-}$is generated by the electron transport chain during seed aging, it is promptly dismutated into hydrogen peroxide $\left(\mathrm{H}_{2} \mathrm{O}_{2}\right)$ by superoxide dismutase (SOD) in the matrix $[5,6] . \mathrm{H}_{2} \mathrm{O}_{2}$ is then eliminated via the various antioxidant pathways that are crucial for the production and scavenging of ROS [7]. In particular, the scavenging of ROS largely depends on the availability of molecular antioxidants such as ascorbic acid (ASC) and glutathione (GSH) in dry seeds [8]. ASC and GSH are necessary to maintain a net reducing environment by reacting with ROS or participating in the ASC-GSH cycle $[9,10]$. Importantly, the ASC-GSH cycle is a crucial detoxifying mechanism in both dry and imbibed seeds, and is principally located in embryos [11]. In the ASC-GSH cycle, ascorbate peroxidase (APX) reduces the toxicity of ROS by using ASC as substrate; ASC is then recycled in the matrix by NADH-dependent monodehydroascorbate reductase (MDHAR) or GSH-dependent dehydroascorbate reductase (DHAR), while GSH can be recycled in the matrix by glutathione reductase (GR) using NADPH as an electron donor [12, 13]. A decline in cellular ASC indicates failing antioxidant capacity during seed aging, hence contributing to a loss of seed viability [14-16]. Similarly, cellular GSH also declines rapidly, with a concomitant rapid decrease in seed vigor, during aging $[4,17,18]$. At the cellular level, seed aging also reduces the activities of several enzymes involved in the ASC-GSH cycle $[16,19]$. Therefore, maintaining high levels of ASC and GSH is important to guarantee vigor in aged seeds.

Mitochondria customarily play a central role in plant metabolism as a major source of adenosine triphosphate (ATP) [20, 21]. Seeds are largely dependent on mitochondrial respiration to provide obligatory energy for their germination [22]. However, the activity of almost all enzymes involved in the tricarboxylic acid cycle decreases significantly during seed aging, e.g., the aging of elm (Ulmus pumila) [23] and rice (Oryza sativa) [24] seeds. Mitochondrial ultrastructure is impaired along with a significant decrease in the activities of cytochrome c oxidase (COX) and malate dehydrogenase (MDH), thereby creating an insufficient supply of mitochondrial energy and a surge in ROS [24]. Consequently, mitochondria play a dominant role in the generation of ROS in seeds [25], and ROS-related mitochondrial dysfunctions play a pivotal role in seed aging [23]. Similar to cellular antioxidant systems, the ASC-GSH cycle is also one of the major antioxidant protection systems in mitochondria under oxidative stresses $[10,26]$. A distinct reduction has been observed in the content of both ASC and GSH and the activities of ASC-GSH cycle enzymes during seed aging $[7,25]$. Nevertheless, there is still only a limited understanding of how to enhance mitochondrial function by improving the antioxidant capacity of the ASC-GSH cycle.
Seed priming can enhance the vigor of aged seeds by efficaciously repairing cellular and mitochondrial components $[27,28]$. The mechanism of priming-enhanced seed longevity is likely associated with antioxidants [29, 30]. Consequently, priming with exogenous antioxidants, e.g., ASC and GSH, may be an important method for effectively improving the vigor of aged seeds. Studies have shown that exogenous ASC clearly promotes the germination of aged seeds in many plants, such as onion (Allium cepa) [31] and Elymus sibiricus [32, 33]. Nonetheless, previous studies rarely focused on the mechanism of exogenous ASC in promoting the germination of aged seeds, particularly at the mitochondrial level. Moreover, exogenous GSH pre-treatment can also improve the germination and antioxidant ability of aged Elymus sibiricus seeds [34], but there are still only a few studies on the role of exogenous GSH in improving the vigor of aged seeds. Therefore, it is necessary to better understand the effect of exogenous ASC and GSH on mitochondrial structures and functions of aged seeds in order to more effectively maintain their vigor.

Oat (Avena sativa), an eco-friendly crop, is widely cultivated throughout the word because it can adapt to a variety of environmental stresses. However, oat grains often have a high lipid content that can easily lead to rancidity or deterioration, hence limits its extensive use as a seed or food $[35,36]$. Therefore, the objectives of this study were to determine the changes in the repair of ultrastructural structures, the enhancement of antioxidant capacity, the remission of lipid peroxidation, the recovery of respiratory functions in embryonic mitochondria of aged oat seeds, and to better understand the response of priming with exogenous ASC and GSH on the mitochondria in aged seeds.

\section{Results}

\section{Effect of ASC and GSH priming on the germination percentage in aged oat seeds}

The germination percentages of oat seeds primed with ASC or GSH after aging were higher than those primed before aging (Fig. 1). There were no significant differences $(P>0.05)$ in the germination percentages between oat seeds primed with ASC, GSH, or ASC + GSH before aging and those aged and non-primed. However, the germination percentages of oat seeds primed with ASC, GSH, or ASC + GSH after aging were significantly $(P<$ $0.05)$ higher than those aged and non-primed. The germination percentage of oat seeds primed with ASC + GSH after aging was significantly $(\mathrm{P}<0.05)$ higher than those primed with GSH after aging, but the germination percentages of oat seeds primed with ASC or ASC + GSH after aging were not significantly $(P>0.05)$ different from those unaged and non-primed. 


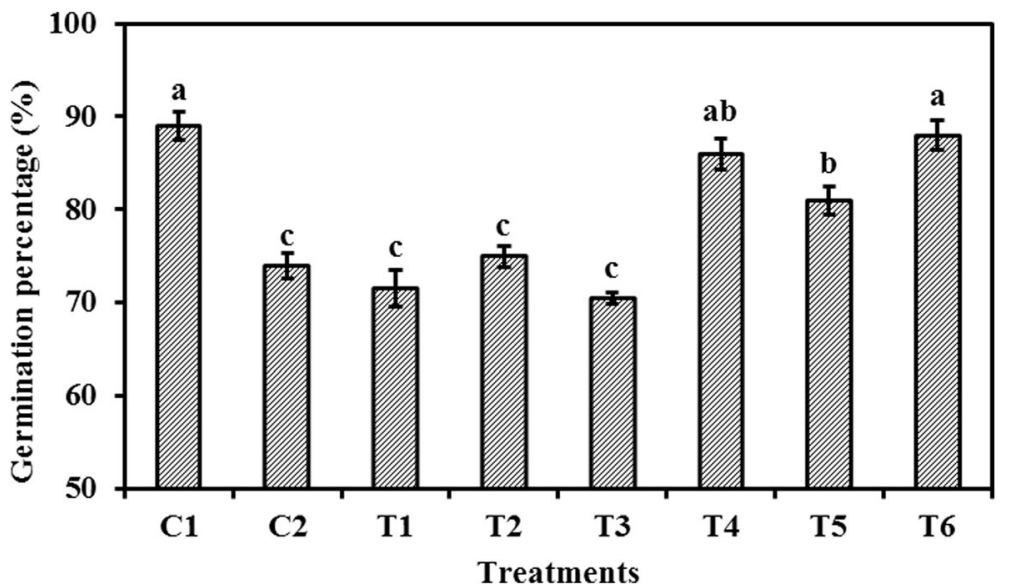

Fig. 1 Effect of ASC or GSH priming on germination percentage of aged oat seeds. C1 unaged, unprimed oat seeds. C2 aged, unprimed oat seeds. T1 oat seeds primed with ASC before aging. T2 oat seeds primed with GSH before aging. T3 oat seeds primed with ASC + GSH before aging. T4 oat seeds primed with ASC after aging. T5 oat seeds primed with GSH after aging. T6 oat seeds primed with ASC + GSH after aging. Means with different letters are significantly different at the 0.05 level among treatments. Vertical bars represent the means of four independent determinations \pm SE

\section{Effect of ASC and GSH priming on the mitochondrial} structure of embryonic root cells in aged oat seeds Ultrastructural observation of embryonic root cells showed that the mitochondrial structures of oat seeds primed with ASC, GSH, or ASC + GSH after aging were superior to those primed before aging (Fig. 2). The mitochondrial structures of embryonic root cells were imperfect in oat seeds primed with ASC or ASC + GSH before aging, and their inner mitochondrial membranes and cristae were indistinct (Fig. 2a and c). The mitochondrial membranes of embryonic root cells were clearly visible in both oat seeds non-primed (aged or unaged) and those primed with GSH before aging. However, their cristae were also indistinct (Fig. 2b, d, and h). Conversely, the mitochondrial membranes and cristae of embryonic root cells were clearly visible in oat seeds primed with ASC or $\mathrm{ASC}+\mathrm{GSH}$ after aging (Fig. 2e and g). The mitochondrial structures of embryonic root cells were also intact in oat seeds primed with GSH after aging, but their double membranes were indistinct (Fig. 2f).

\section{Effect of ASC and GSH priming on mitochondrial} enzymatic activity in embryo cells of aged oat seeds The mitochondrial SOD, APX, MDHAR, DHAR, and GR activities in oat seeds primed with ASC, GSH, or $\mathrm{ASC}+\mathrm{GSH}$ after aging were significantly $(P<0.05)$ higher than in those primed before aging (Fig. 3).

Mitochondrial SOD activities of oat seeds primed with ASC + GSH before aging were significantly $(P<0.05)$ lower than the others, but mitochondrial SOD activities of oat seeds primed with ASC $+\mathrm{GSH}$ after aging were significantly $(\mathrm{P}<0.05)$ higher than the others (Fig. 3a). Mitochondrial SOD activities of aged, non-primed oat seeds were not significantly $(P>0.05)$ different from those primed with GSH before aging. However, mitochondrial SOD activities of non-primed oat seeds (aged or unaged) were significantly $(P<0.05)$ lower than those primed with GSH after aging.

Mitochondrial APX activities of unaged, non-primed oat seeds were significantly $(\mathrm{P}<0.05)$ lower than the others (Fig. 3b). Mitochondrial APX activities of oat seeds primed before aging were not significantly $(P>$ 0.05 ) different from those aged and non-primed, but mitochondrial APX activities of oat seeds primed with ASC or ASC + GSH after aging were significantly $(P<$ 0.05) higher than the others. Mitochondrial APX activities of aged and non-primed oat seeds were significantly $(\mathrm{P}<0.05)$ lower than those primed with GSH after aging.

Mitochondrial MDHAR activities of aged, non-primed oat seeds were not significantly $(P>0.05)$ different from those primed before aging (Fig. 3c). However, mitochondrial MDHAR activities of oat seeds primed with ASC, $\mathrm{GSH}$, or ASC + GSH after aging were significantly higher $(P<0.05)$ than those primed before aging. The highest level of mitochondrial MDHAR activities was found in oat seeds primed with ASC or ASC + GSH after aging. There were no significant $(\mathrm{P}>0.05)$ differences in mitochondrial MDHAR activities between unaged, nonprimed oat seeds and those primed with GSH after aging.

Mitochondrial DHAR activities were highest in unaged, non-primed oat seeds, but were lowest in those primed with ASC or ASC + GSH before aging, and there were no significant $(\mathrm{P}>0.05)$ differences between those primed with ASC and ASC + GSH before aging (Fig. 3d). However, the mitochondrial DHAR activities of oat 

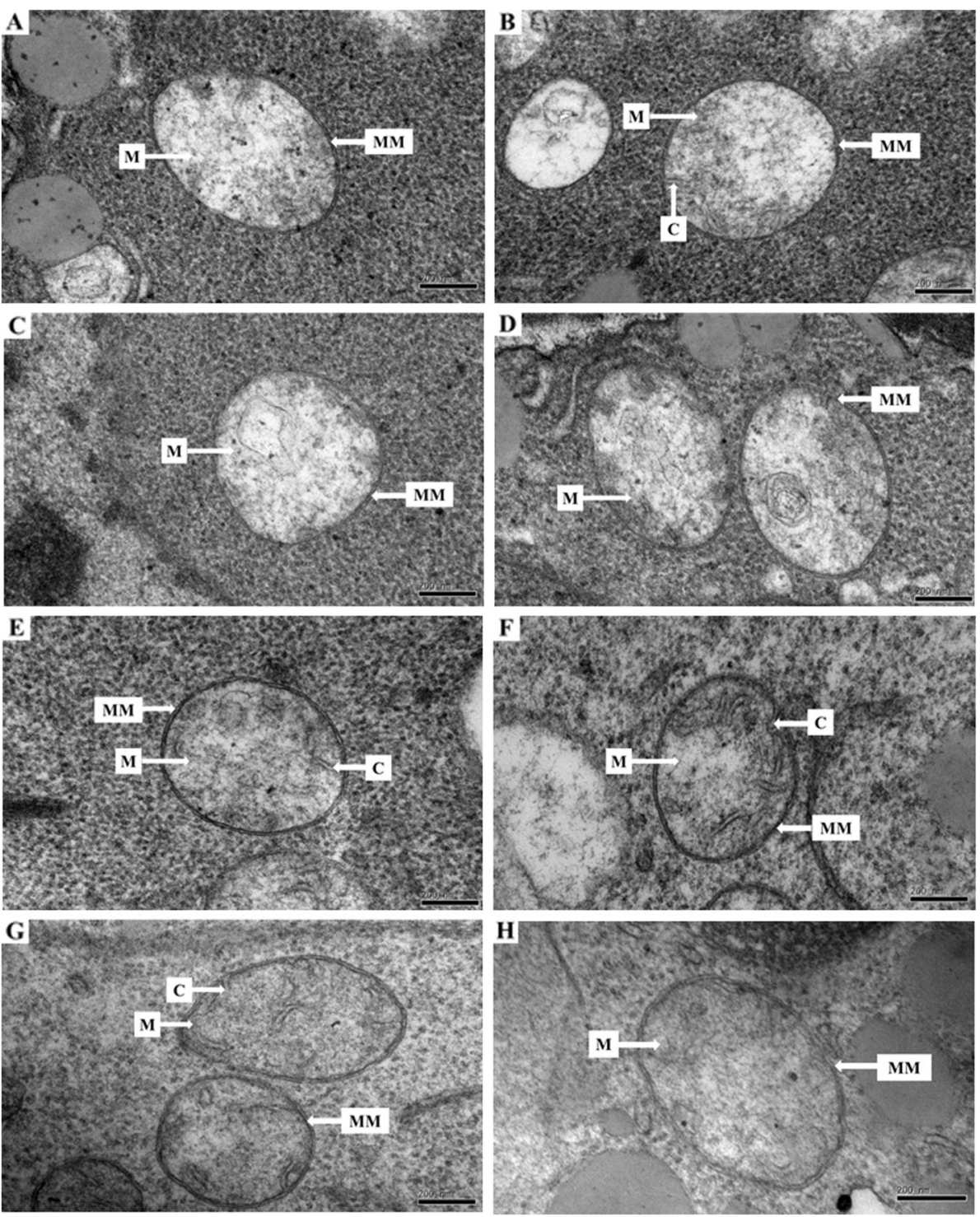

Fig. 2 Effect of ASC or GSH priming on mitochondrial structures of embryonic root cells in aged oat seeds. a oat seeds primed with ASC before aging. $\mathbf{b}$ oat seeds primed with GSH before aging. $\mathbf{c}$ oat seeds primed with ASC + GSH before aging. $\mathbf{d}$ aged, unprimed oat seeds. e oat seeds primed with ASC after aging. F oat seeds primed with GSH after aging. $\mathbf{g}$ oat seeds primed with ASC + GSH after aging. H unaged, unprimed oat seeds. Bars $=200 \mathrm{~nm}$. C cristae. M mitochondria. MM mitochondrial membrane

seeds primed after aging were significantly $(P<0.05)$ higher than those aged and non-primed. Mitochondrial DHAR activities of oat seeds primed with ASC + GSH after aging were significantly $(P<0.05)$ higher than other aged oat seeds. Additionally, mitochondrial DHAR activities were significantly $(P<0.05)$ higher in oat seeds primed with GSH either before or after aging than in those aged and non-primed.

Mitochondrial GR activities were highest in unaged, non-primed oat seeds, but were lowest in those primed with ASC or ASC + GSH before aging (Fig. 3e). However, mitochondrial GR activities of aged, non-primed oat seeds were significantly $(P<0.05)$ lower than those primed with GSH or ASC + GSH after aging.

Effect of ASC and GSH priming on mitochondrial $\mathrm{H}_{2} \mathrm{O}_{2}$ and MDA content in embryo cells of aged oat seeds

Mitochondrial $\mathrm{H}_{2} \mathrm{O}_{2}$ contents of unaged, non-primed oat seeds were significantly $(P<0.05)$ higher than those primed with ASC, GSH, or ASC + GSH after aging, but they were significantly $(\mathrm{P}<0.05)$ lower than those primed before aging and those aged and non-primed (Fig. 4a). Mitochondrial $\mathrm{H}_{2} \mathrm{O}_{2}$ contents were highest in oat seeds primed with ASC + GSH before aging, but they 


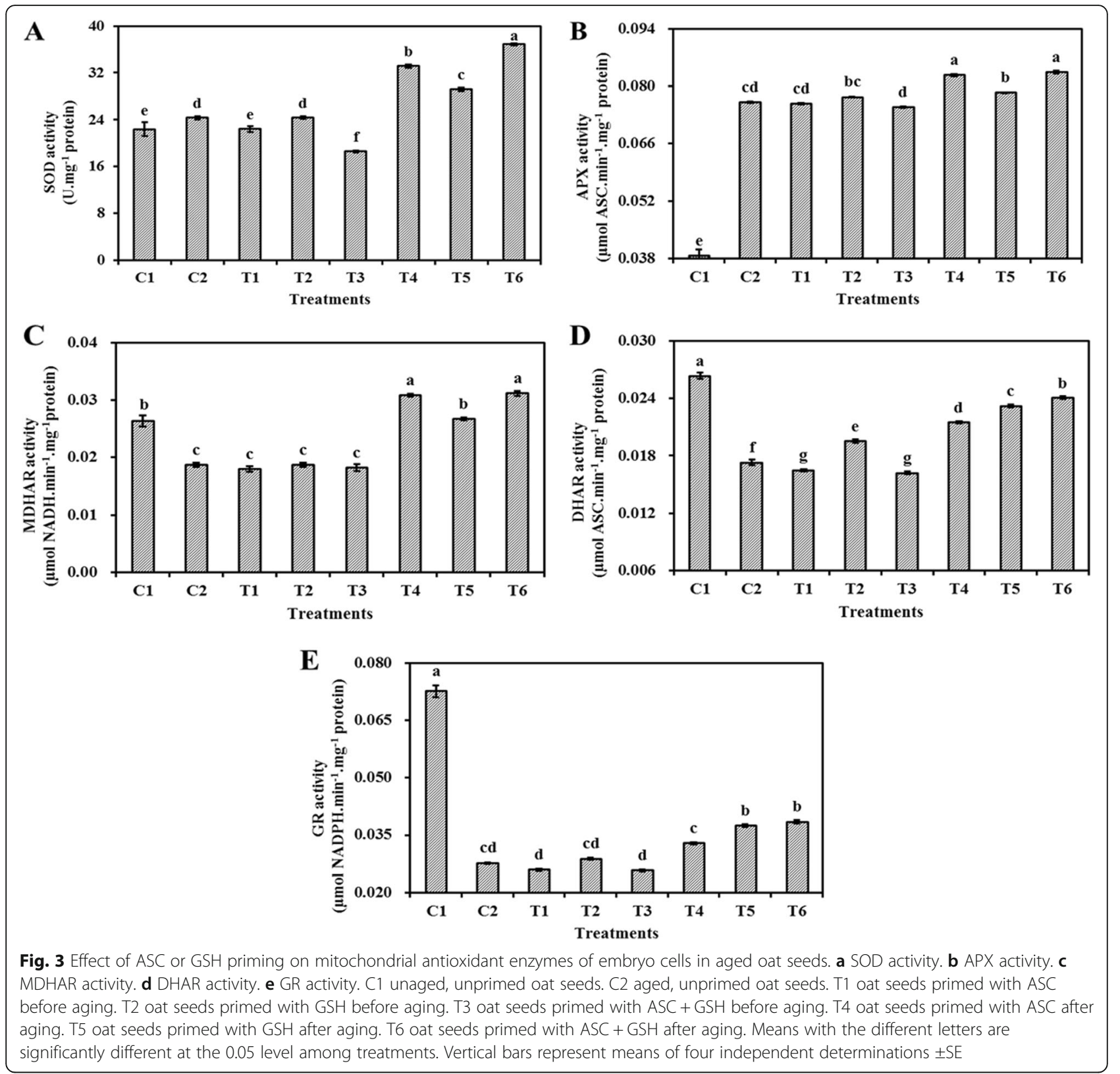

were significantly $(P<0.05)$ lower in oat seeds primed with GSH before aging than those primed with ASC before aging. Mitochondrial MDA contents of unaged, non-primed oat seeds were significantly $(P<0.05)$ lower than the others (Fig. 4b). Mitochondrial MDA contents of oat seeds primed with GSH before aging were significantly $(P<0.05)$ lower than those aged and non-primed, but mitochondrial MDA contents of oat seeds primed with ASC or ASC + GSH before aging were not different from those aged and non-primed. Mitochondrial $\mathrm{H}_{2} \mathrm{O}_{2}$ and MDA contents in oat seeds primed with ASC, GSH, or ASC + GSH after aging were significantly $(P<0.05)$ lower than those aged and non-primed, and the lowest level was observed in those primed with ASC or ASC + GSH after aging.

Effect of ASC and GSH priming on mitochondrial COX and $\mathrm{MDH}$ activities in embryo cells of aged oat seeds

The changes in mitochondrial COX and MDH activities were similar, and the activities of mitochondrial COX and $\mathrm{MDH}$ activities were significantly $(\mathrm{P}<0.05)$ higher in oat seeds primed with ASC, GSH, or ASC + GSH after aging than in those primed before aging (Fig. 5). Mitochondrial $\mathrm{COX}$ and $\mathrm{MDH}$ activities were significantly $(\mathrm{P}<0.05)$ lower in oat seeds primed with ASC or ASC + GSH before aging than in those aged and non-primed, 


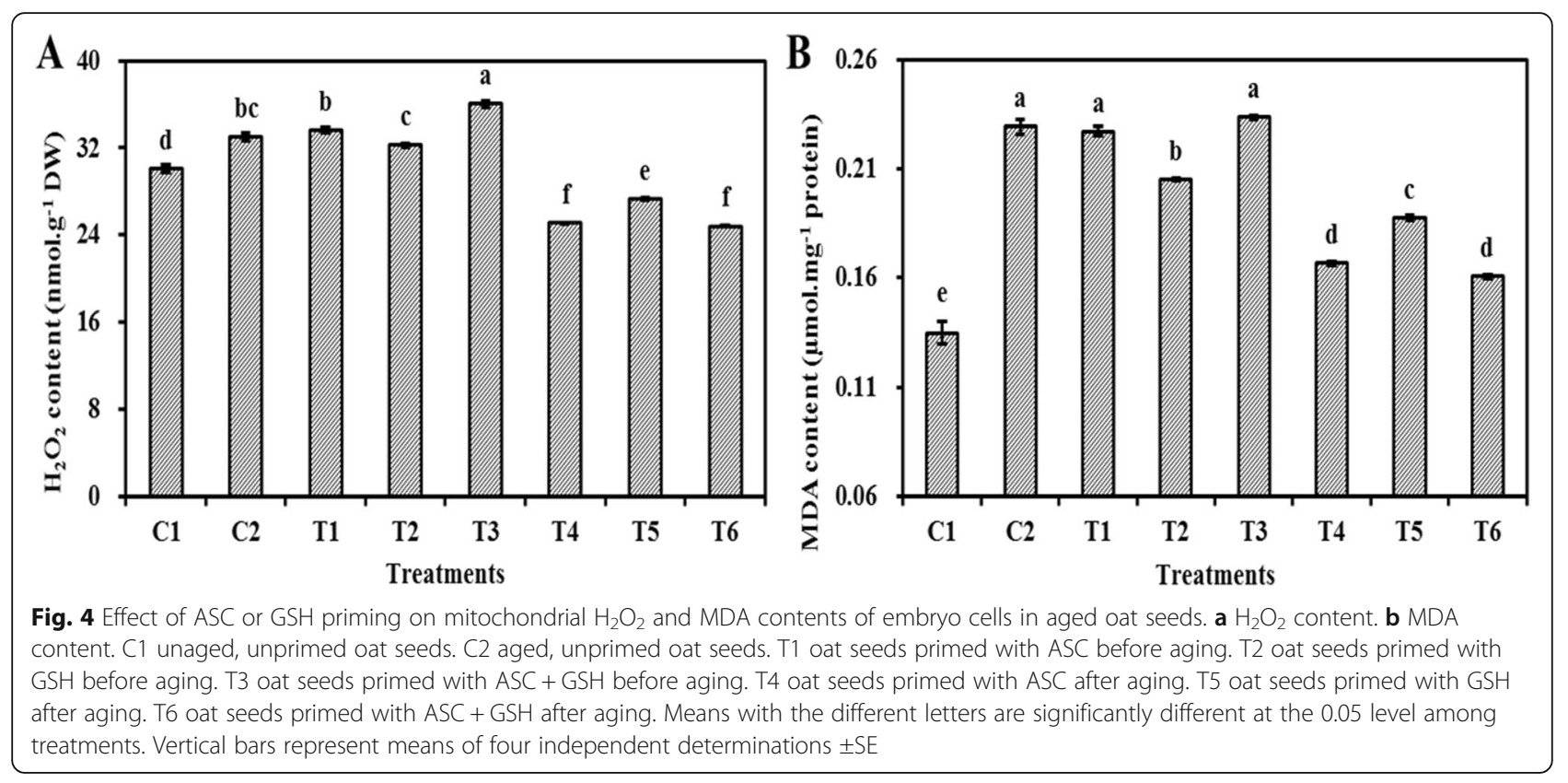

and the lowest level was found in those primed with ASC + GSH before aging. However, mitochondrial COX and $\mathrm{MDH}$ activities were significantly $(\mathrm{P}<0.05)$ higher in oat seeds primed with GSH before aging than in those aged and non-primed. Mitochondrial COX and $\mathrm{MDH}$ activities maintained a high level in oat seeds primed with ASC or ASC + GSH after aging and in those unaged and non-primed.

\section{Discussion}

Fully functional mitochondria often have extensive cristae structures and various biochemical activities [37], and the ASC-GSH cycle is one of the primary antioxidant protection systems in mitochondria under various oxidative stresses (Fig. 6) [39]. However, mitochondrial ultrastructural damage in response to artificial aging negatively impacts mitochondrial function [25]. Previous research also suggests that a decrease in the activities of antioxidant enzymes participating in the ASC-GSH cycle, accompanied by mitochondrial ultrastructural damage, is the major cause of aging in oat seeds [7]. Our current results showed that the negative influence of aging in oat seeds could be effectively repaired by post-priming with ASC, GSH, or ASC + GSH (Fig. 3). Compared to aged and non-primed oat seeds, the mitochondrial SOD, APX, MDHAR, DHAR, and GR activities were all markedly increased in those primed with
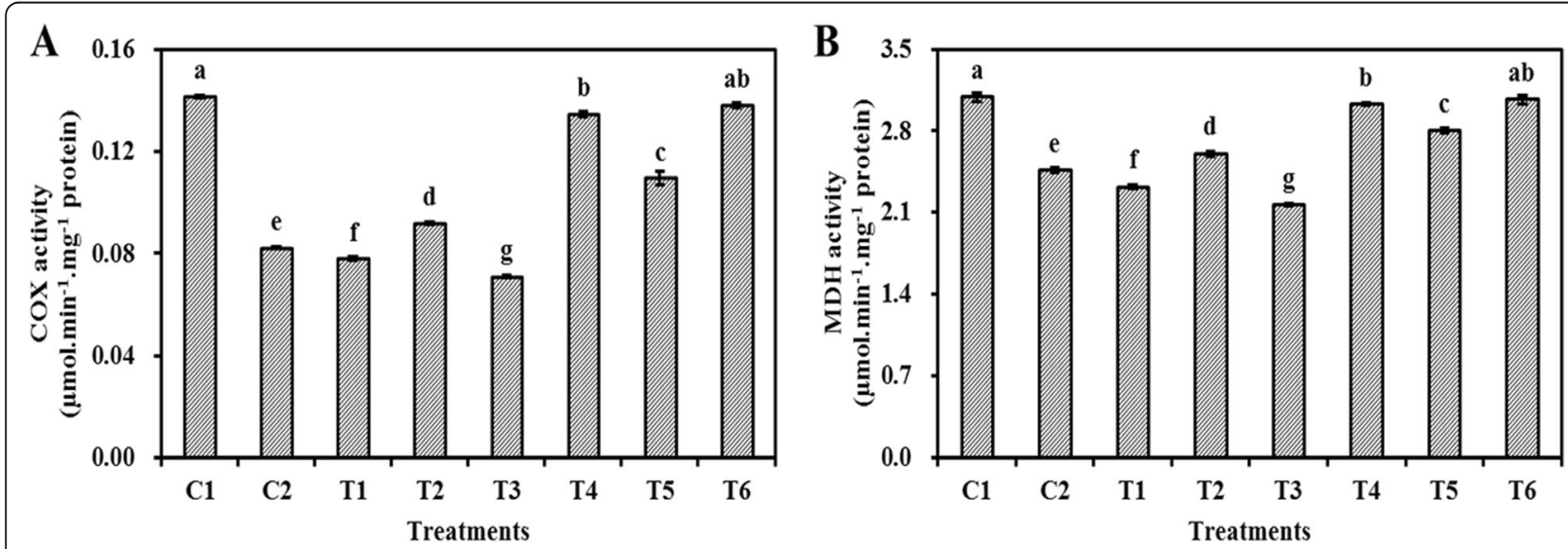

Fig. 5 Effect of ASC or GSH priming on mitochondrial COX and MDH activity of embryo cells in aged oat seeds. a COX activity. b MDH activity. C1 unaged, unprimed oat seeds. C2 aged, unprimed oat seeds. T1 oat seeds primed with ASC before aging. T2 oat seeds primed with GSH before aging. T3 oat seeds primed with ASC + GSH before aging. T4 oat seeds primed with ASC after aging. T5 oat seeds primed with GSH after aging. T6 oat seeds primed with ASC + GSH after aging. Means with the different letters are significantly different at the 0.05 level among treatments. Vertical bars represent means of four independent determinations $\pm \mathrm{SE}$ 


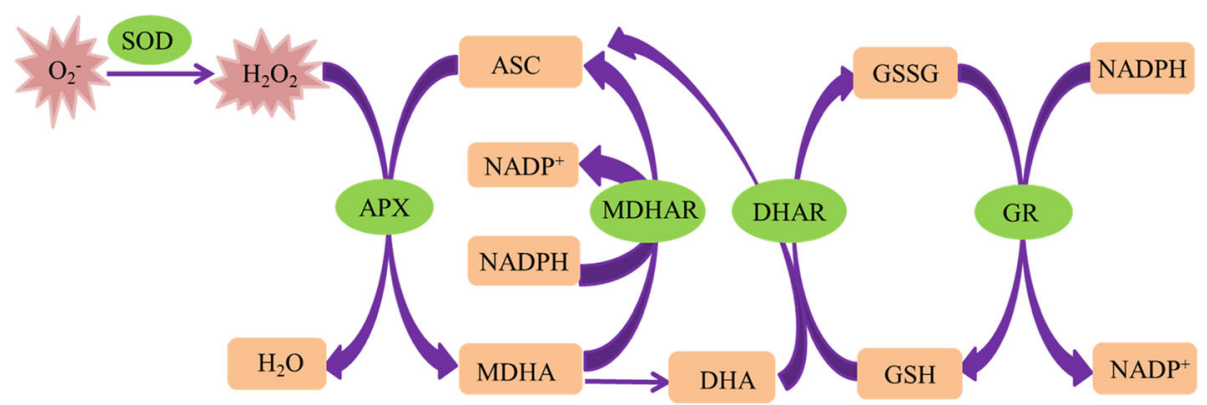

Fig. 6 The ASC-GSH cycle in mitochondrion of plant [38]. SOD superoxide dismutase. $\mathrm{H}_{2} \mathrm{O}_{2}$ hydrogen peroxide. APX ascorbate peroxidase. ASC ascorbic acid. MDHA monodehydroascorbic acid. MDHAR monodehydroascorbic acid reductase. DHA dehydroascorbic acid. DHAR dehydroascorbic acid reductase. GSH glutathione. GSSG oxidized glutathione. GR glutathione reductase

ASC, GSH, or ASC + GSH after aging. Furthermore, the activities of mitochondrial SOD and APX were almost always higher in oat seeds primed with ASC, GSH, or ASC + GSH after aging than in those unaged and non-primed (Fig. 3). These results indicated that priming after aging prevented the depression in antioxidant ability of ASC-GSH cycle' enzymes in oat seeds and was therefore beneficial in supporting the removal of ROS using ASC and GSH. Similarly, priming not only activates existing enzymes, but also improves rRNA integrity, leading to higher levels of protein synthesis in seeds [3]. Consequently, mitochondrial $\mathrm{H}_{2} \mathrm{O}_{2}$ and MDA contents of oat seeds primed with ASC, GSH, or ASC + GSH after aging were also lower than those aged and non-primed (Fig. 4). These results suggested that lipid peroxidation could be effectively relieved in oat seeds by priming with ASC, GSH, or ASC + GSH after aging. Mitochondrial structures of embryonic root cells were obviously restored as cristae gradually emerged in oat seeds primed with ASC, GSH, or ASC + GSH after aging (Fig. 2d-g). This was consistent with our previous findings, which showed that the integrity of the mitochondrial membrane was related to the levels of mitochondrial antioxidants and MDA contents in aged oat seeds [7]. ATP production in mitochondria is the main source of energy during seed germination [25], but oxidative modification can reduce the activities of COX and MDH during seed aging, leading to a decrease in the ATP production [23, 24]. In this study, the activities of mitochondrial $\mathrm{COX}$ and $\mathrm{MDH}$ maintained a high level in oat seeds primed with ASC, GSH, or ASC + GSH after aging, which might have provided more energy for germination (Fig. 5), hence their germination percentage was almost identical to unaged and non-primed seeds (Fig. 1). These positive results indicated that the enhanced germination of aged oat seeds, due to exogenous ASC and GSH, was likely dependent on the improvement of mitochondrial structures and the activation of mitochondrial antioxidant enzymes.

However, positive effects of ASC were not observed in oat seeds primed before aging. Mitochondrial cristae is poorly developed in both dry and imbibed seeds [1]. However, priming with ASC or ASC + GSH before aging provided favorable conditions for the development of mitochondrial structures and functions. Very similar results were reported in pea (Pisum sativum) [40] and soybean (Glycine max) [41] seeds. Unfortunately, seed deterioration appears to be localized first within the mitochondria of meristematic cells [3], where it is more likely to cause serious structural and functional mitochondrial damage. We observed that mitochondrial structures deteriorated in embryonic root cells of oat seeds primed with ASC or ASC + GSH before aging (Fig. 2), which might indicate that their mitochondrial membrane systems were difficult to recover during imbibition [25]. Any changes in mitochondrial morphology will be closely associated with the modification of their functions [42]. Compared to aged, non-primed oat seeds, the activities of mitochondrial antioxidant enzymes were not improved in oat seeds primed with ASC or ASC + GSH before aging (Fig. 3). These conditions were unfavorable for removing ROS in the mitochondria of these seeds, hence their mitochondrial $\mathrm{H}_{2} \mathrm{O}_{2}$ and MDA contents also remained a high level (Fig. 4). Additionally, their $\mathrm{H}_{2} \mathrm{O}_{2}$ and MDA contents were higher than those unaged and non-primed (Fig. 4), culminating in the reduced synthesis of many enzymes and restricted ATP production during their imbibition $[3,43]$. Thus, the activities of COX and $\mathrm{MDH}$ were relatively low in oat seeds primed with ASC or ASC + GSH before aging (Fig. 5), and these seeds could not supply enough energy for germination. The decline in seed germination was most likely due to the degradation of mitochondrial ATP levels in aged soybean [25] and elm [44] seeds. Consequently, the germination percentages of oat seeds primed with ASC or ASC + GSH before aging were not significantly $(P>0.05)$ different from those aged and non-primed, and they were visibly lower than those unaged and non-primed (Fig. 1). These results showed that priming with ASC or ASC + GSH before aging 
could not prevent the occurrence of seed aging, which was consistent with the outcomes of previous studies $[45,46]$. However, compared with oat seeds primed with ASC or ASC + GSH before aging, the activities of mitochondrial SOD, APX, DHAR and GR were enhanced in those primed with GSH before aging (Fig. 3). Additionally, their mitochondrial $\mathrm{H}_{2} \mathrm{O}_{2}$ and MDA contents were reduced (Fig. 4), hence the activities of $\mathrm{COX}$ and $\mathrm{MDH}$ in these seeds were also improved (Fig. 5). GSH is reported to recycle potential ASC via the ASC-GSH cycle (Fig. 6) [39, 47, 48], but this process might take a long time to complete and its effect might also be relatively weak. Mitochondrial structures and functions might therefore also be relatively slow to develop, which might cause mild structural and functional damage for the mitochondria during seed aging [3].

In our study, mitochondrial DHAR and GR activities in oat seeds primed with GSH or ASC + GSH after aging were markedly higher than those primed with ASC after aging (Fig. 3). This indicated that the ASC regeneration maintained a relatively strong level in mitochondria by post-priming with $\mathrm{GSH}$ or ASC + GSH, thereby regulating the balance of redox in the mitochondrial matrix via maintaining ASC in a reduced state (Fig. 6) [39]. This was in agreement with previous studies at the cellular level $[38,49]$. However, mitochondrial SOD, APX, and MDHAR activities of oat seeds primed with GSH after aging were markedly lower than those primed with ASC or ASC + GSH after aging (Fig. 3), and the mitochondrial $\mathrm{H}_{2} \mathrm{O}_{2}$ and MDA contents in these seeds were higher (Fig. 4). These results suggested that the antioxidant capacity of oat seeds primed with GSH after aging was less than those primed with ASC or ASC + GSH after aging, hence their lipid peroxidation was enhanced. Consequently, mitochondrial $\mathrm{COX}$ and $\mathrm{MDH}$ activities of oat seeds primed with GSH after aging were also markedly lower than those primed with ASC or ASC + GSH after aging (Fig. 5), and their germination percentage was also relatively low (Fig. 1). Therefore, these results suggested that the effects of ASC priming were superior to GSH priming for the recovery of aging damage in oat seeds. Previous studies at the cellular level had also demonstrated that the presence of ASC might be crucial for ensuring seed germination [12]. Unexpectedly, the mitochondrial $\mathrm{H}_{2} \mathrm{O}_{2}$ and MDA contents showed no significant $(P>0.05)$ differences between oat seeds primed with ASC and ASC + GSH after aging (Fig. 4), symbolizing a similar level of lipid peroxidation. Thereby, their mitochondrial COX and MDH activities were also not significantly $(\mathrm{P}>0.05)$ different (Fig. 5), showing that they provided similar level of energy for the germination of aged oat seeds, and their germination ability was also not significantly $(\mathrm{P}>0.05)$ different (Fig. 1). These results might imply that positive effects of priming with ASC +
GSH after aging were not superior to post-priming with ASC after aging on injured renovation of aged oat seeds. In other words, the regeneration of ASC was induced by post-priming with GSH in oat seeds, but this effect was not obvious under sufficient ASC conditions.

\section{Conclusions}

Our results suggested that pre-priming with ASC, GSH, or ASC + GSH could not inhibit the aging damage in oat seeds. Fortunately, post-priming with ASC, GSH, or ASC + GSH could effectively repair aging damage in oat seeds, and the effect of ASC priming was greater than GSH priming. However, positive effects of priming with ASC + GSH after aging were not greater than priming with ASC after aging on repairing aging damage of oat seeds.

\section{Methods}

\section{Seed samples}

Oat seeds were collected by the Forage Seed Laboratory of China Agricultural University in 2009 and stored in plastic bags at $-20^{\circ} \mathrm{C}$. The original materials were imported from DYCK Forage \& Grasses LTD of Canada by Beijing Houderui Trading Co., LTD. At the start of the experiment in December 2014, the moisture content of the seeds was $9.8 \%$ (on a fresh-weight basis), the seed germination percentage was $89 \%$, and the oil content of the seeds was $5.0 \%$.

\section{Seed aging and priming treatments}

Seed aging treatments: Primed or non-primed oat seeds with $10 \%$ moisture content on a fresh-weight basis $(45 \%$ relative humidity, $\mathrm{RH}$ ) were immediately sealed in an aluminum foil bag $\left(0.12 \times 0.17 \mathrm{~m}^{2}\right)$ and aged for 20 days at $45^{\circ} \mathrm{C}$ in a water bath.

Seed priming treatments: Oat seeds with 10\% moisture content on a fresh-weight basis $(45 \% \mathrm{RH})$ were soaked in a solution of ASC, GSH, or ASC + GSH at $20^{\circ} \mathrm{C}$ for $0.5 \mathrm{~h}$ (selected from $0,0.5,1,3,6$, and $12 \mathrm{~h}$ ) before or after aging. The concentration of these solutions was 1 $\mathrm{mmol} \mathrm{L}^{-1}$ (selected from $0,0.25,0.5,1,2,4$, and 8 $\mathrm{mmol} \mathrm{L}^{-1}$ ). Thereafter, these seeds were rinsed twice with de-ionized water and air-dried in the dark for 3 days at $25^{\circ} \mathrm{C}$ and $45 \% \mathrm{RH}$ (moisture content reached approximately $10 \%$ on a fresh-weight basis).

Each treatment had four replicates, and 800 oat seeds (approximately $20 \mathrm{~g}$ ) were used for each replicate.

Control 1 (C1) was comprised of unaged, non-primed seeds (approximately 10\% moisture content on a freshweight basis). Control 2 (C2) was comprised of aged, non-primed seeds (approximately 10\% moisture content on a fresh-weight basis). 


\section{Germination tests}

Germination tests were conducted according to International Seed Testing Association rules [50]. Four replicates of 100 seeds from each sample were placed into Petri dishes lined with three filter papers wetted with 10 $\mathrm{mL}$ de-ionized water, and placed in a growth chamber under a constant temperature of $20^{\circ} \mathrm{C}$. Germination was checked daily for 10 days. On day 10 , the final number of normal seedlings was counted, and the length of seedlings was measured.

\section{Ultrastructural observations of mitochondria in embryonic root cells}

Seed samples were selected randomly after different treatments. Embryonic roots, after imbibition for $4 \mathrm{~h}$ and without radicle protrusion, were removed and fixed in a $4 \%$ glutaraldehyde solution for $24 \mathrm{~h}$ and then placed in a refrigerator at $4{ }^{\circ} \mathrm{C}$. The samples of embryonic roots were processed by rinsing with $50 \mathrm{mmol} \mathrm{L}^{-1}$ sodium phosphate buffer, fixing with osmium tetroxide, rinsing with buffer again, dehydrating with an alcohol gradient, and embedding in epoxy resin. After, ultrathin slices were obtained using an LKB8800 III ultramicrotome. Sections were placed on copper grids and stained with $2 \%$ aqueous uranyl acetate for $20 \mathrm{~min}$ followed by a lead electron staining solution (Katayama, Osaka) for $5 \mathrm{~min}$. Twenty results per treatment were observed by the transmission electron microscopy (Hitachi H-7500).

\section{Isolation of mitochondria}

Mitochondrial extraction was carried out by the method of Yin et al. [51]. The specific extract operation was performed as previously described [7]. Part of the enzyme activity that was detected might be due to minimal microsomal contamination from this method.

\section{Enzyme assays}

SOD (EC 1.15.1.1) activity was determined according to Rao and Sresty [42]. APX (EC 1.11.1.11) activity was assayed according to the method of Nakano and Asada [52]. MDHAR (EC1.6.5.4) activity was measured according to Arrigoni et al. [53]. DHAR (EC 1.8.5.1) activity was assayed according to Dalton et al. [54]. GR (EC 1.6.4.2) activity was assayed according to Madamanchi and Alscher [55]. The detailed determination method of SOD, APX, MDHAR, DHAR and GR was also performed as previously described [7]. COX (EC 1.9.3.1) activity was assayed according to Neuburger et al. [56], and was determined as a decrease in absorbance at $550 \mathrm{~nm}\left(\varepsilon_{550}=13.5 \mathrm{mmol}^{-1}\right.$ $\mathrm{cm}^{-1}$ ) and $25^{\circ} \mathrm{C}$ due to cytochrome c oxidation. $\mathrm{MDH}$ (EC 1.1.1.37) activity was measured by monitoring the increase in absorbance at $340 \mathrm{~nm}\left(\varepsilon_{340}=6.2 \mathrm{mmol}^{-1} \mathrm{~cm}^{-1}\right)$ and $25^{\circ} \mathrm{C}$ due to NADH production according to the methods described by Glatthaar et al. [57]. Reaction systems $(1 \mathrm{~mL})$ were mixed with $10 \mu \mathrm{L}$ mitochondria (20 $\mu \mathrm{g}$ mitochondrial protein) in all enzymes assays.

\section{The $\mathrm{H}_{2} \mathrm{O}_{2}$ and malondialdehyde (MDA) contents}

The $\mathrm{H}_{2} \mathrm{O}_{2}$ content of isolated mitochondria was measured by the method of Patterson et al. [58]. The determination was depened on the changes in absorbance values of the titanium peroxide complex at $415 \mathrm{~nm}$, which was calculated from a standard curve of known $\mathrm{H}_{2} \mathrm{O}_{2}$ concentrations.

MDA content of isolated mitochondria was measured by the method of Bailly et al. [59], which was calculated by the determining absorbance values at 532 and $600 \mathrm{~nm}$. $100 \mu \mathrm{L}$ isolated mitochondria were mixed into $3 \mathrm{~mL}$ reaction systems, which contained $20 \%(\mathrm{w} / \mathrm{v})$ trichloroacetic acid and $0.5 \%(\mathrm{w} / \mathrm{v}) 2$-thiobarbituric acid.

\section{Statistical analyses}

Comparisons of mean differences in different treatments were carried out through an analysis of variance (ANOVA), using SPSS for Windows version 13.0. Duncan's multiple range test $(P=0.05)$ was used to compare the treatment means of physiological indicators for antioxidant systems and lipid peroxidation.

\section{Abbreviations \\ APX: Ascorbate peroxidase; ASC: Ascorbate acid; ATP: Adenosine triphosphate; COX: Cytochrome c oxidase; DHAR: Dehydroascorbate reductase; GR: Glutathione reductase; GSH: Glutathione; MDA: Malondialdehyde; MDH: Malate dehydrogenase; MDHAR: Monodehydroascorbate reductase;" RH: Relative humidity; ROS: Reactive oxygen species; SOD: Superoxide dismutase.}

\section{Acknowledgements}

We thank all of our colleagues in our laboratory for providing useful discussions and technical assistance. We are very grateful to the editor and reviewers for critically evaluating the manuscript and providing constructive comments for its improvement. We are also very grateful to Radia Lyna Lahlou and Brendan Nuse for their careful improvement of the manuscript language.

\section{Authors' contributions}

FX and PM conceived and designed the research. FX and $\mathrm{HC}$ conducted the experiments. $\mathrm{LC}$ and $\mathrm{HZ}$ contributed new reagents and analytical tools. FX and MW analyzed the data. FX and PM wrote the manuscript. All authors read and approved the manuscript.

\section{Funding}

This work was financially supported by the Natural Science Foundation of China (NSFC31702171, NSFC 31572454), the Natural Science Foundation of Shanxi (201701D221154), and the Science and Technology Innovation Fund of Shanxi Agricultural University (2016YJ15). The funding agencies provided only the experimental costs and publication fee for this work. Funds were used for the design of the study and collection, analysis, and interpretation of data and in writing the manuscript, as well as in the open access payment.

\section{Availability of data and materials}

The datasets used and/or analysed during the current study available from the corresponding author on reasonable request.

Ethics approval and consent to participate

These plant materials are widely used all over the world, and no permits are required for the collection of plant samples. The plant materials were 
collected by the Forage Seed Laboratory of China Agricultural University, China. This article did not contain any studies with human participants or animals, and did not involve any endangered or protected species.

\section{Consent for publication}

Not applicable.

\section{Competing interests}

The authors declare that they have no competing interests.

\section{Author details}

'College of Animal Science and Veterinary Medicine, Shanxi Agricultural University, Taigu 030801, China. ${ }^{2}$ Forage Seed Laboratory/Beijing Key Laboratory of Grassland Science, China Agricultural University, No 2, Yuanmingyuan West Road, Haidian Distr, Beijing 100193, China.

Received: 10 May 2019 Accepted: 28 February 2020

Published online: 06 March 2020

\section{References}

1. Bewley JD, Bradford KJ, Hilhorst HWM, Nonogaki H. Seeds: Physiology of Development, Germination and Dormancy. 3rd ed. New York: Springer Press; 2013. p. 363-7.

2. Gao J, Fu H, Zhou X, Chen Z, Luo L, Cui B, et al. Comparative proteomic analysis of seed embryo proteins associated with seed storability in rice (Oryza sativa L) during natural aging. Plant Physiol Bioch. 2016;103:31-44.

3. McDonald MB. Seed deterioration: physiology, repair and assessment. Seed Sci Technol. 1999:27:177-237.

4. Chen H, Osuna D, Colville L, Lorenzo O, Graeber K, Küster H, et al. Transcriptome-wide mapping of pea seed ageing reveals a pivotal role for genes related to oxidative stress and programmed cell death. PLoS One. 2013;8:1-15.

5. Iturbe-Ormaetxe I, Matamoros MA, Rubio MC, Dalton DA, Becana M. The antioxidants of legume nodule mitochondria. Mol Plant Microbe In. 2001;14: 1189-96.

6. Rubio MC, James EK, Clemente MR, Bucciarelli B, Fedorova M, Vance CP, et al. Localization of superoxide dismutases and hydrogen peroxide in legume root nodules. Mol Plant Microbe In. 2004;17:1294-305.

7. Xia F, Wang X, Li M, Mao P. Mitochondrial structural and antioxidant system responses to aging in oat (Avena sativa L.) seeds with different moisture contents. Plant Physiol Biochem. 2015;94:122-9.

8. Pukacka S, Ratajczak E. Age-related biochemical changes during storage of beech (Fagus sylvatica L.) seeds. Seed Sci Res. 2007;17:45-53.

9. Noctor $\mathrm{G}$, Foyer $\mathrm{CH}$. Ascorbate and glutathione: keeping active oxygen under control. Annu Rev Plant Physiol Pant Mol Biol. 1998;49:249-79.

10. Gupta SD. Reactive oxygen species and antioxidants in higher plants. New York: CRC press; 2011. p. 50-4.

11. DePaula M, PerezOtaola M, Darder M, Torres M, Frutos $G$ MartinezHonduvilla CJ. Function of the ascorbate-glutathione cycle in aged sunflower seeds. Physiol Plant. 1996;96:543-50.

12. Tullio MCD, Arrigoni $O$. The ascorbic acid system in seeds: to protect and to serve. Seed Sci Res. 2003;13:249-60.

13. Wu JH, Wang WQ, Song SQ, Cheng HY. Reactive oxygen species scavenging enzymes and down-adjustment of metabolism level in mitochondria associated with desiccation-tolerance acquisition of maize embryo. J Integr Plant Biol. 2009;51:638-45.

14. Tommasi F, Paciolla C, de Pinto MC, Gara LD. Effects of storage temperature on viability, germination and antioxidant metabolism in Ginkgo biloba L. seeds. Plant Physiol Biochem. 2006;44:359-68.

15. Hu D, Ma G, Wang Q, Yao J, Wang Y, Pritchard HW, et al. Spatial and temporal nature of reactive oxygen species production and programmed cell death in elm (UImus pumila L.) seeds during controlled deterioration. Plant Cell Environ. 2012;35:2045-59.

16. Xia F, Chen L, Sun Y, Mao P. Relationships between ultrastructure of embryo cells and biochemical variation during ageing of oat (Avena sativa L.) seeds with different moisture content. Acta Physiol Plant. 2015:37:1-11.

17. Seal CE, Zammit R, Scott P, Flowers TJ, Kranner I. Glutathione half-cell reduction potential and a-tocopherol as viability markers during the prolonged storage of Suaeda maritime seeds. Seed Sci Res. 2010;20:47-53.
18. Long RL, Kranner I, Panetta FD, Birtic S, Adkins SW, Steadman KJ. Wet-dry cycling extends seed persistence by re-instating antioxidant capacity. Plant Soil. 2011;338:511-9.

19. Yin G, Xin X, Song C, Chen X, Zhang J, Wu S, et al. Activity levels and expression of antioxidant enzymes in the ascorbate-glutathione cycle in artificially aged rice seed. Plant Physiol Biochem. 2014;80:1-9.

20. Berkowitz O, De Clercq I, Breusegem FV, Whelan J. Interaction between hormonal and mitochondrial signaling during growth, development and in plant defence responses. Plant, Cell and Environment. 2016;39:1127-39.

21. Taylor NL. Editorial for special issue "plant mitochondria". Int J Mol Sci. 2018; 19:3849-54.

22. Sew YS, Ströher E, Fenske R, Millar AH. Loss of mitochondrial malate dehydrogenase activity alters seed metabolism impairing seed maturation and post-germination growth in Arabidopsis. Plant Physiol. 2016;171:849-63.

23. Li Y, Wang Y, Xue H, Pritchard HW, Wang X. Changes in the mitochondrial protein profile due to ROS eruption during ageing of elm (UImus pumila L.) seeds. Plant Physiol Biochem. 2017:114:72-87.

24. Yin G, Whelan J, Wu S, Zhou J, Chen B, Chen X, et al. Comprehensive mitochondrial metabolic shift during the critical node of seed ageing in rice. PLoS One. 2016;11:1-19.

25. Xin X, Tian Q, Yin G, Chen X, Zhang J, Ng S, et al. Reduced mitochondrial and ascorbated-glutathione activity after artificial ageing in soybean seed. J Plant Physiol. 2014;171:140-7.

26. Jacoby RP, Li L, Huang S, Lee CP, Millar AH, Taylor NL. Mitochondrial composition, function and stress response in plants. J Integr Plant Biol. 2012;54:887-906.

27. Xia FS, Chen LL, Yan HF, Sun Y, Li ML, Mao PS. Antioxidant and ultrastructural responses to priming with PEG in aged, ultra-dry oat seed. Seed Sci Technol. 2016:44:1-13.

28. Xia FS, Wang MY, Chen LL, Cheng H, Sun Y, Li ML, et al. Responses of mitochondrial ultrastructure and physiological variations to PEG-priming on ultra-dried oat (Avena sativa L.) seeds after ageing. Seed Sci Technol. 2017; 45:622-37.

29. Bailly C, Benamar A, Corbineau F, Côme D. Free radical scavenging as affected by accelerated ageing and subsequent priming in sunflower seeds. Physiol Plant. 1998;104:6467-652.

30. Yeh YM, Sung JM. Priming slows deterioration of artificially aged bitter gourd seeds by enhancing antioxidative activities. Seed Sci Technol. 2008; 36:350-9.

31. Kumari P, Sheoran IS, Tomar RPS. Onion seed longevity as affected by ascorbic acid treatments during ambient storage. Haryana J Hortic Sci. 2004 33:257-60.

32. Yan HF, Xia FS, Sun Y, Mao PS. Protective effect of ascorbic acid on seedling growth and embryo cellular ultrastructure in aged Elymus sibiricus seeds. Seed Sci Technol. 2015:43:1-13.

33. Yan HF, Mao PS, Sun Y, Li ML. Impacts of ascorbic acid on germination, antioxidant enzymes and ultrastructure of embryo cells of aged Elymus sibiricus seeds with different moisture contents. Int J Agric Biol. 2016;18:17683.

34. Yan HF, Mao CL, Zhu YQ, Cheng H, Mao PS. Exogenous glutathione pretreatment improves germination and resistance of Elymus sibiricus seeds subjected to different ageing conditions. Seed Sci Technol. 2017;45:607-21.

35. Heini RL, Oksman-Caldentey KM, Lehtinen $P$, Lehtinen $P$, Poutanen K. Effect of drying treatment conditions on sensory profile of germinated oat. Cereal Chem. 2001;78:707-14.

36. Claudine C, Tom S, Susan RV, Stewart D. Comparison of two headspace sampling techniques for the analysis of off-flavour volatiles from oat based products. Food Chem. 2012;134:1592-600.

37. Carrie C, Murcha MW, Giraud E, Ng S, Zhang MF, Narsai R, et al. How do plants make mitochondria? Planta. 2013;237:429-39.

38. Foyer $\mathrm{CH}$, Noctor $\mathrm{G}$. Ascorbate and glutathione: the heart of the redox hub. Plant Physiol. 2011;155:2-18.

39. Jiménez A, Hernández JA, del Río LA, Sevilla F. Evidence for the presence of the ascorbate-glutathione cycle in mitochondria and peroxisomes of pea leaves. Plant Physiol. 1997;114:275-84.

40. Benamar A, Tallon C, Macherel D. Membrane integrity and oxidative properties of mitochondria isolated from imbibing pea seeds after priming or accelerated ageing. Seed Sci Res. 2003;13:35-45.

41. Sun H, Li L, Wang X, Wu S, Wang X. Ascorbate-glutathione cycle of mitochondria in osmoprimed soybean cotyledons in response to imbibitional chilling injury. J Plant Physiol. 2011;168:226-32. 
42. Rao KVM, Sresty TVS. Antioxidant parameters in the seedlings of pigeon pea (Cajanus cajan (L.) Millspaugh) in response to Zn and Ni stresses. Plant Sci. 2000;157:113-28.

43. Daum B, Walter A, Horst A, Osiewacz HD, Kuhlbrandt W. Age-dependent dissociation of ATP synthase dimers and loss of inner-membrane cristae in mitochondria. Proc Natl Acad Science USA. 2013;110:15301-6.

44. Wang $Y, L i Y, X$ ue H, Pritchard HW, Wang X. Reactive oxygen speciesprovoked mitochondrial-dependent cell death during ageing of elm (UImus pumila L.) seeds. Plant J. 2015;81:438-52.

45. Chhetri DR, Drrai AS, Bhattacharjee A. Chemical manipulation of seed longevity of 4 crop species in an unfavorable storage environment. Seed Sci Technol. 1993;21:31-44.

46. Draganić I, Lekić S. Seed priming with antioxidants improves seed germination and seedling growth under unfavorable germination conditions. Turk J Agric For. 2012;36:421-8.

47. Foyer $\mathrm{CH}$, Noctor $\mathrm{G}$. Redox homeostasis and antioxidant signaling: a metabolic interface between stress perception and physiological responses. Plant Cell. 2005;17:1866-75

48. Szalai G, Kellös T, Galiba G, Kocsy G. Glutathione as an antioxidant and regulatory molecule in plants under abiotic stress conditions. J Plant Growth Regul. 2009;28:66-80.

49. Gill SS, Tuteja N. Reactive oxygen species and antioxidant machinery in abiotic stress tolerance in crop plants. Plant Physiol Biochem. 2010;48:90930.

50. ISTA. In: International Seed Testing Association, editor. International rules for seed testing. Bassersdorf; 2014

51. Yin GK, Sun HM, Xin X, Qin GZ, Liang Z, Jing XM. Mitochondrial damage in the soybean seed axis during imbibition at chilling temperatures. Plant Cell Physiol. 2009;50:1305-18.

52. Nakano Y, Asada K. Hydrogen peroxide scavenged by ascorbate-specific peroxidase in spinach chloroplast. Plant Cell Physiol. 1981;22:867-80.

53. Arrigoni $\mathrm{O}$, Dipiero $\mathrm{S}$, Borraccino G. Ascorbate free radical reductase: a key enzyme of the ascorbic acid system. FEBS Lett. 1981;125:242-4.

54. Dalton DA, Baird LM, Langeberg L, Taugher $C Y$, Anyan WR, Vance $C P$, et al. Subcellular localization of oxygen defense enzymes in soybean (Glycine max (L.) Merr.) root nodules. Plant Physiol. 1993;102:481-9.

55. Madamanchi NR, Alscher RG. Metabolic bases for differences in sensitivity of two pea cultivars to sulfur dioxide. Plant Physiol. 1991;97:88-93.

56. Neuburger M. Preparation of plant mitochondria, criteria for assessment of mitochondrial integrity and purity, survival in vitro. In: Douce R, Day D, editors. Higher Plant Cell Respiration. Berlin: Springer-Verlag; 1985. p. 7-24.

57. Glatthaar BE, Barbarsah GR, Noyes BE, Banaszak LJ, Bradshaw RA. The preparation of the cytoplasmic and mitochondrial forms of malate dehydrogenase and aspartate aminotransferase from pig heart by a single procedure. Anal Biochem. 1974;57:432-51.

58. Patterson BD, Macrae EA, Ferguson IB. Estimation of hydrogen peroxide in plants extracts using titanium (IV). Anal Biochem. 1984;139:487-92.

59. Bailly C, Benamar A, Corbineau F, Côme D. Changes in malondialdehyde content and superoxide dismutase, catalase and glutathione reductase activities in sunflower seeds as related to deterioration during accelerated aging. Physiol Plant. 1996;97:104-10.

\section{Publisher's Note}

Springer Nature remains neutral with regard to jurisdictional claims in published maps and institutional affiliations.

\section{Ready to submit your research? Choose BMC and benefit from:}

- fast, convenient online submission

- thorough peer review by experienced researchers in your field

- rapid publication on acceptance

- support for research data, including large and complex data types

- gold Open Access which fosters wider collaboration and increased citations

- maximum visibility for your research: over $100 \mathrm{M}$ website views per year

At $\mathrm{BMC}$, research is always in progress.

Learn more biomedcentral.com/submissions 